\title{
PARP/Tankyrase Inhibitor 2X-121
}

National Cancer Institute

\section{Source}

National Cancer Institute. PARP/Tankyrase Inhibitor 2X-121. NCI Thesaurus. Code C102746.

An orally available small molecule inhibitor of the nuclear enzymes poly (ADP-ribose) polymerase (PARP) 1 and 2, with potential antineoplastic activity. Upon administration, E7449 selectively binds to PARP 1 and 2, thereby preventing the repair of damaged DNA via the base excision repair (BER) pathway. This agent enhances the accumulation of single and double strand DNA breaks and promotes genomic instability eventually leading to apoptosis. PARP 1/2 inhibitor E7449 may enhance the cytotoxicity of DNA-damaging agents and of radiotherapy. PARP catalyzes post-translational ADP-ribosylation of nuclear proteins that signal and recruit other proteins to repair damaged DNA. 